\title{
LID RETRACTION IN THE NON-PARETIC EYE IN ACQUIRED OPHTHALMOPLEGIA*
}

\author{
BY
}

\author{
I. S. JAIN
}

Institute for Post-graduate Medical Education and Research, Chandigarh, India

Paradoxical lid retraction of the ptotic lid on occlusion of the sound eye and several other synkinetic oculopalpebral phenomena are described in the literature in relation to ophthalmoplegia, congenital as well as acquired (Lewallen, 1958; Walsh, 1957). Fuchs's phenomenon of lid retraction on lateral movement, the pseudo-Graefe phenomenon with depression and lid retraction on elevation, are all observed in the ptotic eye.

In a very few reported cases lid retraction occurs in the sound eye, when there is ptosis of the opposite lid. This retraction of the upper lid is an example of secondary deviation, proved by the fact that covering the ptotic eye is followed by a return to normal of the retracted upper lid of the nonparetic eye.

\section{Case Report}

A 30-year-old man was first seen in the Out-patients Department of this Institute on September 14, 1962, with the complaint of pain over the right eye-brow and inability to raise the right upper lid of 4 weeks' duration.

On August 14 he had a sudden attack of severe pain over the right supra-orbital region, which lasted for several hours; 2 days later the right upper lid drooped down and he could not open the eye. The pain became less, but a dull ache persisted over the right eye-brow.

The patient was a migrainous subject and had been having attacks of headache since the age of 15 years.

Examination.-The visual acuity was $6 / 9$ ptly in the right eye and 6/9 in the left uncorrected. The ocular tension was $20 \mathrm{~mm}$. $\mathbf{H g}$ in each eye. The right upper lid covered more than half of the cornea. The left eye showed lid retraction.

The pupils were of equal size, and reacted both to light and on convergence.

The right eye was divergent, and slightly hypotropic with loss of all movements except abduction. Marked intorsion of the right eye on attempted depression proved the integrity of the fourth nerve, and a diagnosis was made of right third nerve paresis causing external ophthalmoplegia.

The ocular movements of the left eye were full.

There was no exophthalmos and the visual fields and fundi were normal.

* Received for publication January 22, 1963. 
Investigations.-The central nervous system, urine, blood, total and differential white cell count, erythrocyte sedimentation rate, Wassermann reaction and Kahn test were normal. The fasting blood sugar was $86 \mathrm{mg}$. per cent.

Radiological Studies.-A right arteriogram did not reveal any aneurysm and ventriculographic studies were negative.

Diagnosis.-A diagnosis of ophthalmoplegic migraine was supported by the fact that the patient had had typical attacks of migrainous hemicrania for the past 15 years, and had a negative arteriogram.

The retraction of the upper lid could not be explained, as the patient had no symptoms or signs of thyrotoxicosis, nor of a mid-brain lesion, and the condition occurred after ophthalmoplegia in the right eye. It was thought that the levator of the eye was acting as a "yoke muscle" as the patient was making an effort to raise the ptosed right lid, thus causing a secondary deviation of the left upper lid (Fig. 1).

To prove this point, the ptosed right eye was patched tightly for 3 days, and the left eye was carefully watched for any change in the width of the palpebral fissure. After 72 hours, the left upper lid came down to its normal position (Fig. 2).

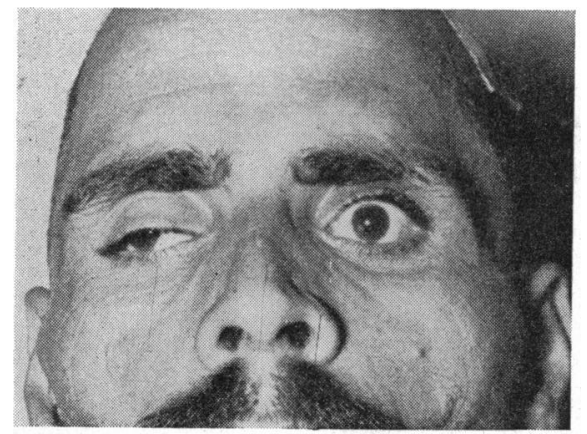

Fig. 1.-Paralytic ptosis right eye and secondary lid retraction left eye.

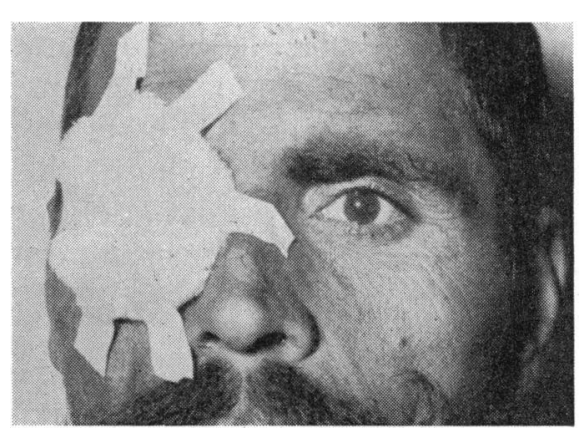

Fig. 2.-Right eye occluded, left lid retraction disappears.

\section{Discussion}

Widening of the palpebral fissure is observed as a result of increased size of the eye, as in high myopia, or in congenital glaucoma. In exophthalmic goitre, the widening is probably due to tonic contraction of the smooth muscles in the eye-lids. It is seen in facial paralysis and sometimes in lesions of the mid-brain. It may be observed as part of the re-generation phenomenon after paralysis of the third nerve, and in myasthenia gravis. It may also be caused physiologically by fear or stress.

Here attention is drawn to its occurrence where there is ptosis of the opposite eye-lid. This retraction demonstrates the secondary deviation of the non-paretic levator palpebrae of the opposite eye.

Walsh (1957) has observed this situation in two patients with myasthenia gravis, and in one case he showed staring of the normal eye when the other eye showed pronounced ptosis. 
Lewallen (1958) reported a similar case in which the ophthalmoplegia was due to trauma, but he thought that for this syndrome to occur there must be a defective vision in the non-ptotic eye and the paralysed eye must be the master eye. He did not think it would occur if the vision were normal in both eyes.

In the present case, the vision was about equal in each eye, thus proving that the presence of depressed visual acuity in the non-paretic eye is not necessary to show this phenomenon. The levators are not commonly thought of as extra-ocular muscles, and no mention is made in the text-books of their working as synergists. This case suggests that they do in fact function as "yoke" muscles.

\section{REFERENCES}

LeWAI.LEN, W. M., Jr. (1958). Amer. J. Ophthal., 45, 565.

WALSH. F. B. (1957). "Clinical Neuro-ophthalmology", 2nd ed., p. 196. Williams and Wilkins, Baltimore. 